\title{
A EDUCAÇÃo AMBIENTAL E A ESCOLA NO PROCESSO DE CONSTRUÇÃO DA RESPONSABILIDADE SOCIOAMBIENTAL
}

Ronaldo Desiderio Castange ${ }^{1}$, Fátima Aparecida Dias Gomes Marin ${ }^{2}$

\begin{abstract}
${ }^{1}$ Mestre em Educação pela Universidade Estadual Paulista - Unesp, campus de Presidente Prudente. Atualmente é doutorando em educação pela mesma instituição, Presidente Prudente, SP. E-mail: castange@live.com

${ }^{2}$ Doutora em Ensino na Educação Brasileira pela Universidade Estadual Paulista - Unesp, campus de Marília. Atualmente é docente do Departamento de Educação e do Programa de Pós-Graduação em Educação da Universidade Estadual Paulista - Unesp, campus de Presidente Prudente.
\end{abstract}

\section{RESUMO}

Apresentamos neste trabalho um recorte dos resultados da nossa pesquisa de mestrado, de caráter documental, por meio da qual avaliamos 15 livros paradidáticos voltados à questão ambiental, com especial atenção para a questão dos Resíduos Sólidos/Lixo. Entre os conceitos que observamos estão os de Reutilização, Reciclagem e Sustentabilidade. Tivemos como objetivo discutir a relevância dos livros paradidáticos como importantes aliados do trabalho docente na escola. Pudemos perceber que, apesar de apresentarem potencialidades que facilitam a inserção das discussões voltadas à Educação Ambiental no contexto escolar, os livros possuem inúmeras fragilidades, como a apresentação de conceitos de forma superficial ou a confusão entre conceitos como reutilização e reciclagem, o que ressalta a importância do papel do professor e da escola. Consideramos a escola como um espaço educador, de modo que a Educação Ambiental na escola contribui para a construção da responsabilidade socioambiental e para a aquisição de valores e atitudes alinhados à conservação ambiental.

Palavras-chave: Espaço Educador, Educação Ambiental, Responsabilidade Socioambiental, Livros Paradidáticos.

\section{ENVIRONMENTAL EDUCATION AND THE SCHOOL IN THE CONSTRUCTION PROCESS OF SOCIO- ENVIRONMENTAL RESPONSIBILITY}

\begin{abstract}
We present in this paper some results of our masters research, of a documentary nature, where we evaluated 15 environmental books focused on the environmental issue, with special attention to the issue of Solid Waste / Garbage. Among the concepts we observe are Reuse, Recycling and Sustainability. We had as objective to discuss the relevance of the text books as important allies of the teaching work in the school. We can see that, although they present potentialities that facilitate the insertion of the discussions focused on Environmental Education in the school context, the books have numerous fragilities, such as the presentation of concepts in a superficial way or the confusion between concepts such as reuse and recycling, which importance of the role of teacher and school. We consider the school as an educational space, so that Environmental Education at school contributes to the construction of social and environmental responsibility and to the acquisition of values and attitudes aligned with environmental conservation.
\end{abstract}

Keywords: Educator Space, Socio-environmental Responsibility, Environmental Education, Text Books.

\section{LA EDUCACIÓN AMBIENTAL Y LA ESCUELA EN EL PROCESO DE CONSTRUCCIÓN DE RESPONSABILIDAD SOCIAL Y AMBIENTAL}




\section{RESUMEN}

Presentamos en este trabajo un recorte de los resultados de nuestra investigación de maestría, de carácter documental, mediante la cual evaluamos 15 libros ambientales centrados en el tema ambiental, con especial atención al tema de Residuos Sólidos / Basura. Entre los conceptos que observamos se encuentran la reutilización, el reciclaje y la sostenibilidad. Tuvimos como objetivo discutir la relevancia de los libros paradidáticos como importantes aliados del trabajo docente en la escuela. Podemos ver que, aunque presentan potencialidades que facilitan la inserción de las discusiones centradas en la Educación Ambiental en el contexto escolar, los libros tienen numerosas fragilidades, como la presentación de conceptos de manera superficial o la confusión entre conceptos como reutilización y reciclaje, que Importancia del papel del profesor y de la escuela. Consideramos la escuela como un espacio educativo, por lo que la Educación Ambiental en la escuela contribuye a la construcción de la responsabilidad social y ambiental y a la adquisición de valores y actitudes alineadas con la conservación ambiental.

Palabras clave: Espacio para Educadores, Educación Ambiental, Responsabilidad Socioambiental, Libros para-literarios.

\section{INTRODUÇÃO}

Podemos compreender a Educação Ambiental como "uma prática de conscientização capaz de chamar a atenção para a finitude e a má distribuição dos recursos naturais e envolver cidadãos em ações sociais ambientalmente apropriadas" (CARVALHO, 2006, p. 52). Desta forma, deve auxiliar na compreensão das contradições, problemas e conflitos, favorecendo uma visão integradora entre o ambiente e o homem. Assim, a Educação Ambiental deve servir como emancipadora do ideário consumista e capitalista e materializar-se em conhecimentos, habilidades e atitudes voltados à conservação do ambiente que devem ser aprendidos desde a infância e levados para toda a vida.

Entre os conceitos difundidos dentro da questão ambiental estão o desenvolvimento sustentável e a sustentabilidade. 0 primeiro trata-se, nas palavras de Gadotti (2012, p. 43), de "um processo de transformação no qual a exploração dos recursos, a direção dos investimentos, a orientação do desenvolvimento tecnológico e a mudança institucional se harmonizam e reforçam o potencial presente e futuro, a fim de atender as necessidades e aspirações humanas". Em se tratando do segundo, o autor cita o equilíbrio com o outro e com a natureza, o cuidado com o planeta, já que "a sustentabilidade que defendemos refere-se ao próprio sentido do que somos, de onde viemos e para onde vamos, como seres humanos" (GADOTTI, 2012, p. 46).

O consumo segue direção oposta ao ideário de sustentabilidade, ao passo que cada vez mais se usurpa os recursos naturais disponíveis para dar conta de uma superprodução voltada para um superconsumo que, consequentemente, gera acúmulo de resíduos e degradação ambiental. Diante disso, Sachs (2000, p. 29) exalta que "uma nova forma de civilização, fundamentada no aproveitamento sustentável dos recursos renováveis, não é apenas possível, mas essencial".

Sachs (2000) acena para a necessidade de desenvolver uma Educação Ambiental consciente e transformadora, valorizando as problemáticas locais e buscando soluções para seu enfrentamento, de forma coletiva. Somamos a isso as palavras de Benfica $(2008$, p. 7$)$ ao dizer que "o desenvolvimento sustentável tem grande componente educativo: a preservação do meio ambiente depende de uma consciência ecológica e a formação da consciência depende da educação".

Para isso, Pelicioni (2000, p. 19) reitera:

A Educação Ambiental deve, portanto, capacitar os indivíduos ao pleno exercício da cidadania, permitindo a formação de uma base conceitual suficientemente

diversificada técnica e culturalmente, de modo a permitir que sejam superados os obstáculos à utilização sustentável do meio [...] Nos níveis formais e informais tem procurado desempenhar esse difícil papel resgatando valores como - respeito à vida e à natureza, entre outros. 
O modelo de escola como conhecemos hoje, tem seu surgimento a partir das transformações ocasionadas pela Revolução Francesa, como explica Borges (2011, p. 11), a educação, por sua vez, "é tão antiga quanto a própria capacidade do ser humano em aprender", desta maneira "tudo o que acontece na vida do ser humano é dotado de um enorme potencial educativo" (p. 11). Por isso a autora aponta a necessidade e a

Importância de consolidarmos uma visão ampliada de educação, capaz de ressignificar os espaços e os tempos, além de respeitar e valorizar a diversidade de atores e suas respectivas responsabilidades para com a sustentabilidade da vida. Uma educação que vá além dos muros escolares, que dialogue com as famílias, que englobe as comunidades $\mathrm{e}$ as transforme, ao mesmo tempo em que revisite seu papel e suas práticas (BORGES, 2011, p. 11).

De acordo com Borges (2011, p. 12):

O desafio que se impõe à escola neste início de século está posto: trata-se da capacidade de agir e reagir frente às mudanças socioambientais globais; de refletir sobre as ocorrências e de interpretar os fatos; de assumir uma postura ética e responsável diante dos reiterados avisos da bioesfera de que é hora de parar e mudar as maneiras de agir, produzir e consumir.

Em outras palavras, tem-se a necessidade de as escolas se tornarem espaços educadores sustentáveis, que como explica Czapski e Trajber (2010, p. 27) são:

Espaços que mantêm uma relação equilibrada com o meio ambiente e compensam seus impactos com o desenvolvimento de tecnologias apropriadas, de modo a garantir qualidade de vida para as gerações presentes e futuras. Permitindo maior qualidade de vida, esses espaços educam por si e irradiam sua influência para as comunidades nas quais se situam.

Dessa forma, tornar $\mathrm{O}$ espaço "integrador, educador e sustentável" (BORGES, p. 16), consiste também "transformar a escola em um espaço de vivência, a partir da aquisição de saberes, da troca de experiências e de ações voltadas para o envolvimento da comunidade escolar como protagonista de uma cultura de responsabilidade ética." (MARIN, 2008, p. 127).

Outrossim, é necessário pensar em um importante tripé quando se pretende estabelecer um ambiente educador sustentável no espaço escolar: o currículo, a gestão e o espaço físico. Discussões e decisões tomadas no papel devem somar-se a práticas que contribuam para sua efetivação, modificando, o tanto quanto for possível, dentro das limitações espaciais e financeiras, os espaços escolares e a maneira de olhar e cuidar destes, "isso se torna mais fácil quando se tem um sonho compartilhado e um engajamento coletivo em realizá-lo. " (MOREIRA, 2011, p. 19)

Em se tratando do currículo, a autora afirma que "o desafio curricular é exercitar o pensar e o agir global e localmente, no marco das mudanças ambientais nas quais a escola e a comunidade se inserem" (MOREIRA, 2011, p. 21). Deste modo:

A inserção curricular da Educação Ambiental no Projeto Político Pedagógico da escola, de forma inter e transdisciplinar, promove a construção do conhecimento com uma postura crítica, ética e transformadora de valores que reorientem atitudes para a construção de sociedades sustentáveis (MOREIRA, 2011, p. 21). 
Nas palavras de Trajber (2011, p. 24) "a Educação Ambiental se torna, assim, uma política pública voltada para o futuro que, tendo as escolas como referência de espaços educadores para suas comunidades, educa para sociedades sustentáveis".

A Educação Ambiental é proposta desde o ensino infantil até o ensino médio de maneira contínua e de variados modos. O Art. 10 da Lei no 9795/99 determina que a Educação Ambiental seja entendida como:

Os processos por meio dos quais o indivíduo e a coletividade constroem valores sociais, conhecimentos,

habilidades, atitudes e competências voltadas para a manutenção do meio ambiente, bem de uso comum do povo, essencial à sadia qualidade de vida e sua sustentabilidade (BRASIL, 1999).

Como afirma Campos et al. (2013, p. 30483)

A Educação Ambiental
inserida no currículo
escolar desde a Educação
Infantil tem função
importante no processo
de conscientização do ser
humano, para que o
mesmo possa cultivar ao
longo sua trajetória
acadêmica o sentimento
de respeito e preservação
ambiental. Os professores,
juntamente com toda
gestão escolar, possuem
papel fundamental nesse
processo de aprendizagem
e na construção dessa
consciência ambiental.

Os livros e a escola são potenciais informadores e articuladores de conhecimentos e práticas passíveis de assimilação pelas crianças. Assim, a Educação Ambiental, que deve estar presente no currículo de forma transversal e contínua, pode ser estimulada e desenvolvida, a partir da leitura de livros paradidáticos.

Suas histórias, ilustrações e personagens chamam a atenção dos pequenos fazendo-os ativar sua imaginação. Por esse motivo, acreditamos que a inserção da Educação Ambiental pode ser realizada desde a Educação Infantil, por meio destes livros, incentivando a leitura, escrita e imaginação e transmitindo e aprofundando conceitos de maneira lúdica.

\section{METODOLOGIA}

Nossa investigação de mestrado buscou e avaliou livros paradidáticos em bibliotecas de cinco escolas municipais das diferentes zonas da cidade de Presidente Prudente - SP: norte, sul, leste, oeste e centro. Encontramos 16 obras que evidenciam a temática ambiental, com especial atenção para a questão dos Resíduos Sólidos.

Como proposta para a realização deste trabalho, enfocamos, portanto, a pesquisa documental. Como explicam Ludke e André (1986, p. 38) é um tipo de metodologia "pouco explorada não só na área da educação como em outras áreas das ciências sociais". Sá-Silva, Almeida e Guindani $(2009$, p. 2) salientam:

$\mathrm{O}$ uso de documentos em pesquisa deve ser apreciado e valorizado. A riqueza de informações que deles podemos extrair e resgatar justifica o seu uso em várias áreas das Ciências Humanas e sociais porque possibilita ampliar o entendimento de objetos cuja compreensão necessita de contextualização histórica e sociocultural.

Seguindo a mesma linha, Cellard (2008, p. 298) considera que "a análise documental favorece a observação do processo de maturação ou de evolução de indivíduos, grupos, conceitos, conhecimentos, comportamentos, mentalidades, práticas, entre outros".

Em nossa pesquisa verificamos como os livros paradidáticos apresentavam os conceitos de consumo, reutilização, reciclagem, sustentabilidade, lixo, matéria-prima, processos de produção, geração de resíduos, destinação final, cooperativas, a ideia de ciclo, poluição e doenças, além das formas de disposição e tratamento dos resíduos sólidos como o acondicionamento, lixão, aterro controlado, aterro sanitário, incineração, compostagem. Dado o espaço para apresentação das informações neste artigo, apresentamos os 
conceitos de reutilização, reciclagem e sustentabilidade.

RESULTADOS E DISCUSSÃO

Quadro 1. Conceitos acerca da Educação ambiental nos livros paradidáticos

\begin{tabular}{|c|c|c|c|}
\hline \multirow[b]{2}{*}{ Título do livro } & \multicolumn{3}{|c|}{ Conceitos abordados } \\
\hline & 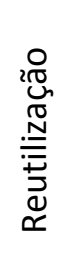 & 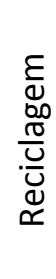 & 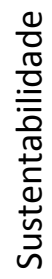 \\
\hline \multicolumn{4}{|l|}{ A aventura de uma garrafa } \\
\hline \multicolumn{4}{|l|}{ A poluição } \\
\hline \multicolumn{4}{|l|}{ Ajude a natureza } \\
\hline \multicolumn{4}{|l|}{ Aprendendo com a natureza } \\
\hline \multicolumn{4}{|l|}{ Chico Papeleta e a reciclagem de papel } \\
\hline \multicolumn{4}{|l|}{ Jogue lixo no lixo } \\
\hline \multicolumn{4}{|l|}{ Meu brinquedo é diferente } \\
\hline \multicolumn{4}{|l|}{ No parque Nosso Verde } \\
\hline \multicolumn{4}{|l|}{ O gato, o porco e a porcaria } \\
\hline \multicolumn{4}{|l|}{$\mathrm{O}$ gigante monstruoso do lixo } \\
\hline \multicolumn{4}{|l|}{ O lixo na lixeira } \\
\hline \multicolumn{4}{|c|}{ O menino que quase morreu afogado no lixo } \\
\hline \multicolumn{4}{|c|}{ O pneu chorão } \\
\hline \multicolumn{4}{|l|}{ O saci e a reciclagem do lixo } \\
\hline \multirow{2}{*}{\multicolumn{4}{|c|}{$\begin{array}{l}\text { Vamos abraçar o mundinho } \\
\text { Apresenta e explica a questão }\end{array}$}} \\
\hline & & & \\
\hline
\end{tabular}

Fonte: Pesquisa de Campo (2017).

Podemos compreender a reutilização como "o emprego direto de um resíduo com a mesma finalidade para a qual foi originalmente concebido, sem a necessidade de tratamento que altere suas características físicas ou químicas (MANSOR et al., 2010, p. 21)", ou seja, o reaproveitamento de materiais já descartados sendo utilizados para outras finalidades, por exemplo, o uso do pneu como uma floreira ou o uso de garrafa pet como porta lápis.

Este conceito é abordado por sete dos 15 livros. Observamos aprofundamento nos títulos "A aventura de uma garrafa", "Chico Papeleta e a reciclagem do papel", "O lixo na lixeira" e "O pneu chorão". Chamamos atenção para a obra "O lixo na lixeira" por ser a única que aborda de forma significativa a questão da redução do consumo e da reutilização de forma completa. Leva as crianças a perceberem que até roupas podem ser reaproveitadas e que podemos e devemos repensar nosso consumo dentro da discussão de embalagens, obsolescências e
O quadro, a seguir, sintetiza parte dos resultados que obtivemos com a pesquisa, especificamente com referência aos conceitos de reutilização, reciclagem e sustentabilidade. necessidades. As obras "A poluição", "Meu brinquedo é diferente" e "Vamos abraçar o mundinho" apresentam o conceito sem aprofundamentos.

O conceito de reutilização é comumente confundido com o de reciclagem, que se trata do resultado de uma série de atividades nas quais materiais que iriam para o lixo são separados e processados para que voltem a serem matérias primas (JARDIM; WELSS, 1995).

O conceito de reciclagem é abordado por 11 das 15 obras. Observamos aprofundamento em seis delas, sendo estas "A aventura de uma garrafa", "Chico Papeleta e a reciclagem do papel", "O gigante monstruoso do lixo", "O lixo na lixeira", "O pneu chorão" e "O saci e a reciclagem do lixo". Nas obras "A poluição", "Jogue lixo no lixo", "No parque Nosso Verde", "O gato, o porco e a porcaria" e "Vamos abraçar o mundinho" o conceito é citado de forma superficial. 
A ideia de sustentabilidade, que sugere atender as necessidades atuais da humanidade sem comprometer a natureza e os recursos das gerações futuras, é aprofundada pelo livro "Chico Papeleta e a reciclagem do papel" e deixada nas "entrelinhas" em outras quatro obras "O gato, o porco e a porcaria", "O pneu chorão", "O saci e a reciclagem do lixo" e "Vamos abraçar o mundinho", de forma que se percebe a ideia da sustentabilidade nas ações das personagens, mas o conceito não é explicado.

Verificamos que se trata de um conceito relativamente novo, acompanhando o avanço das preocupações globais acerca da problemática ambiental, contudo, esbarra muitas vezes em interesses econômicos.

Percebemos que todos os conceitos que nos propomos a observar permeiam os livros encontrados, contudo, na maioria das vezes, sem o aprofundamento ou explicações necessárias. As obras que menos contribuem para a compreensão da temática são "Ajude a natureza", "Aprendendo com a natureza" e "O menino que quase morreu afogado no lixo", que não desenvolvem de forma satisfatória nenhum dos conceitos. Já os livros "Chico Papeleta e a reciclagem do papel", "O lixo na lixeira" e "O saci e a reciclagem do lixo" são os livros que mais contribuem para a compreensão dos conceitos pelas crianças. Os demais livros se encontram em situação mediana.

O papel do professor como mediador dos conhecimentos é necessário para garantir que os conceitos relevantes para o entendimento do tema Resíduos Sólidos/Lixo sejam tratados, com o devido aprofundamento. Entendemos que os livros paradidáticos são excelentes pontos de partida para a discussão com as crianças, por despertarem a curiosidade e o interesse em aprender.

Pensando que temos de agir para o enfrentamento da crise socioambiental já no presente, transformar a escola em um espaço educador sustentável não pode ser deixado para - futuro. Nossa proposta de apresentar conhecimentos acerca da Educação Ambiental de forma lúdica, desde a educação infantil, por meio de livros Paradidáticos vai ao encontro disso. Acreditamos que as informações referentes ao meio ambiente, devam ser apresentadas:

Não com a intenção de chocar nem de paralisar as pessoas, como têm feito as divulgações midiáticas com seus discursos, em sua maioria, catastrofistas. A ideia é, ao contrário, que a educação utilize a repercussão desses eventos recentes em um sentido afirmativo, positivo, transformador, que, por um lado, mobiliza para a ação cuidadora, protetora e preventiva e, por outro, prepara para a reação e adaptação diante de eventos extremos inevitáveis, para que não se tornem de fato desastres, com perdas humanas e ambientais imensuráveis (BORGES, 2011, p. 15).

É neste sentido que alertamos para a necessidade de se envolver a comunidade escolar em pautas locais de problemas ambientais que vivenciam, para que compreendam e se envolvam com soluções passíveis de serem tomadas no coletivo, isso sem deixar de lado questões de caráter global.

Gírio (2010) explica que as crianças necessitam de vivências, seja observando, comparando, pesquisando, relacionando, de forma a construir conhecimentos no sentido de "cuidar para que não falte", o que atribui importante papel ao espaço escolar e a equipe escolar.

A função de conceber
espaços educadores
dentro das escolas é
relevante, considerando
que a partir dessa
experiência (no espaço e
no tempo) poderão surgir
novas possibilidades de
conformações sociais, haja
vista que essas práticas
devam ser significativas e
possibilitadoras do
desenvolvimento das
capacidades intelectuais e
manuais integradas dos
indivíduos que delas
participam e, também,
indiretamente de outros.
(OLIVEIRA, 2012, p. 136).

Alguns exemplos de escolas que se tornaram espaços educadores sustentáveis 
podem ser observados no Brasil. ${ }^{1}$ A Creche Municipal Hassis, em Florianópolis, que gera energia por painéis solares e reaproveita a água da chuva. O Colégio Positivo Internacional, em Curitiba foi projetado para economizar $45 \%$ da água potável e $74 \%$ da energia elétrica por meio de inúmeras ações tecnológicas sustentáveis. Estas escolas, além da estrutura funcional sustentável, praticam ações que envolvem os alunos e os permitem vivenciar a sustentabilidade por meio de hortas, de oficinas de reciclagem e de reaproveitamento de materiais.

\section{CONSIDERAÇÕES FINAIS}

Estando a questão ambiental ligada aos modos atuais de produção e consumo, é necessário voltarmos nossas atenções para os resíduos sólidos, com destaque para os impactos ambientais relacionados à extração de matérias primas da natureza e à geração de resíduos em todas as etapas do processo produtivo e do descarte.

Entendemos que a Educação Ambiental não deva ser simplesmente ensinada, mas vivenciada e neste sentido concordamos com o pensamento de Penteado (1994) ao compreender a escola como um espaço substancial de promoção da consciência ambiental por meio da junção de questões socioculturais e ambientais, de modo que as aulas ofereçam conhecimentos aos alunos e desencadeiem experiências e vivências.

Como afirma Logarezzi (2004), na maioria das vezes se aborda a questão dos resíduos apenas no momento após sua geração, ou seja, não se discute a questão do consumo, de repensar o que se consome, de preferir produtos com menos embalagens e de se reutilizar estas embalagens. Notamos este fato como uma das principais fragilidades nos livros paradidáticos analisados, estando presente em nove das 15 obras.

É importante ressaltar a confusão conceitual entre reutilização e reciclagem, pudemos observar em nossas análises. Lembramos que reciclar consiste em reinserir os materiais no processo produtivo, substituindo o uso de novas matérias-primas. Já reutilizar consiste em usar de outra forma um material que não serve mais para a finalidade original a qual

Reportagem do site SustentArqui. Disponível em: http://sustentarqui.com.br/construcao/10-escolas-sustentaveis/. Acesso em 23, jun., 2018. foi pensado, como, por exemplo, fazer brinquedos com garrafas pet, latas, rolos de papel e outros.

Como potencialidade, todos os livros são passíveis de terem os conceitos voltados à Educação Ambiental em Resíduos Sólidos aprofundados ou ainda inseridos no contexto da aula. Muitos dos livros explicam a ideia de ciclo, levando à compreensão de todo o processo que envolve a fabricação de um produto, desde a extração das matérias-primas até a destinação final dos resíduos. Notamos que isso é melhor explicado nos livros que tratam de apenas um material, como o vidro, o papel ou mesmo o pneu.

Percebemos que os livros, em sua maioria, trazem informações voltadas ao desenvolvimento de procedimentos e atitudes adequadas por parte das crianças para com o meio ambiente.

Por este motivo, os conceitos voltados à Educação Ambiental em Resíduos Sólidos são importantes, pois permitem às crianças o saber, e a Educação Ambiental torna-se fundamental por explicar estes conceitos, permitindo às crianças o saber fazer, tudo isso visando que elas possam ser agentes transformadoras do meio ambiente, com atitudes voltadas à sustentabilidade.

Acreditamos que os livros paradidáticos são importantes por contribuírem, de forma lúdica, com a disseminação de conhecimentos acerca da Educação Ambiental ainda na infância, sendo um importante aliado na construção de um espaço educador sustentável, contudo, por apresentarem lacunas e confusões conceituais, precisam ser trabalhados cuidadosamente pelo professor, com aprofundamentos e esclarecimentos que favoreçam a compreensão dos conceitos e dos processos envolvidos. Neste sentido, a escola desempenha importante papel na construção da responsabilidade socioambiental a partir da disseminação de uma Educação Ambiental crítica, transformadora e vivenciada.

\section{REFERÊNCIAS}

BENFICA, G. Sustentabilidade e Educação. Revista Virtual de Letras e Cultura. 2008. Disponível em: http://www.seara.uneb.br/sumario/professores/ gregoriobenfica.pdf. Acesso em 02 jul. 2018.

BORGES, C. O que são espaços educadores sustentáveis. Espaços Educadores Sustentáveis, v. 21 , n. 07, p. 11-17, jun. 2011. Disponível em: 
http://www.nuredam.com.br/files/documentos mec/194055espacoseducadoressustentaveis.pdf. Acesso em: 18 jan. 2018.

BRASIL. Lei no 9.795, de 27 de abril de 1999. Dispõe sobre a educação ambiental, institui a Política Nacional de Educação Ambiental e dá outras providências. Diário Oficial da União, Brasília, 27 abr. 1999. Disponível em: <http://www.planalto.gov.br/ccivil_03/leis/19795 .htm>. Acesso em 22 nov. 2014.

CAMPOS, E. P.; SANTOS, J. P.; FARIAS, C. D.; PIRES, E. D. P. B.; RIBEIRO, R. M. Educação Ambiental: um despertar de uma consciência coletiva desde a educação infantil. In: CONGRESSO NACIONAL DE EDUCAÇÃO, 11, 2013, Curitiba. Anais... Curitiba: Champagnat, 2013. p. 30483-30491. Disponível em: http://educere.bruc.com.br/ANAIS2013/trabalho s_1.html. Acesso em: 17 jan. 2015.

CARVALHO, I. C. M. Educação Ambiental: a formação do sujeito ecológico. 2 ed. São Paulo: Cortez, 2006.

CELLARD, A. A análise documental. In: POUPART, J. et al. A pesquisa qualitativa: enfoques epistemológicos e metodológicos. Petrópolis, Vozes, 2008. p. 295-316.

CZAPSKI, S.; TRAJBER, R. Macrocampo de Educação Ambiental. Brasília: Ministério da Educação, 2010.

GADOTTI, M. Educar para a sustentabilidade. São Paulo: Instituto Paulo Freire, 2012.

GÍRIO, M. G. C. A preservação do meio ambiente na educação infantil. Disponível em: <http://www.neteducacao.com.br/portal_novo/? pg=artigo\&cod=1705>. Acesso em: 02 jul. 2018.

JARDIM, N. S.; WELSS, C. Lixo municipal: manual de gerenciamento integrado. São Paulo: IPT/CEMPRE, 1995.

LOGAREZZI, A. Contribuições conceituais para o gerenciamento de resíduos sólidos e ações de Educação Ambiental. In: LEAL, A. C.; GONÇALVES, M. A.; IKUTA, F. A.; ZANIN, M.; LOGAREZZI, A. J.; FERREIRA, E. R.; BARBOSA, T. Resíduos sólidos no Pontal do Paranapanema. Presidente Prudente: Editora Viena, 2004. p. 219-246.
LUDKE, M.; ANDRÉ, M. E. D. A. Pesquisa em educação: abordagens qualitativas. São Paulo: EPU, 1986

MANSOR, M. T. C.; CAMARÃO, T. C. R. C.; CAPELINI, M.; KOVACS, A.; FILET, M.; SANTOS, G. A.; SILVA, A. B. Cadernos de Educação Ambiental: Resíduos Sólidos. São Paulo: Governo do Estado de São Paulo, 2010.

MARIN, F. A. D. G. Educação Ambiental em resíduos sólidos na escola: saberes e ações para a sustentabilidade. In: Metodologia de projetos na Educação Ambiental. FISCARELLI, S. H.; AKAMATSU, J. I. (Org.). São Paulo: UNESP, 2008. p. 127-149.

MOREIRA, T. Escola sustentável: currículo, gestão e edificação. Espaços Educadores Sustentáveis, v. 21, n. 07, p. 17-22, jun. 2011. Disponível em: http://www.nuredam.com.br/files/documentos_ mec/194055espacoseducadoressustentaveis.pdf. Acesso em: 18 jan. 2018.

OLIVEIRA, A. Espaço educador: um conceito em formação. 2012. 161f. Dissertação (Mestrado em Tecnologia). Universidade Estadual de Campinas, Faculdade de Tecnologia, 2012. Disponível em: http://www.bibliotecadigital.unicamp.br/docume nt/?code=000852378. Acesso em: 02 jul. 2018.

PELICIONI, M. C. F. Educação em Saúde e Educação Ambiental - estratégias de construção da Escola Promotora da Saúde. 2000. 185f. Tese (Livre-docência em Saúde Pública) - Faculdade de Saúde Pública, Universidade de São Paulo, São Paulo, 2000.

PENTEADO, H. D. Meio ambiente e formação de professores. São Paulo: Cortez, 1994.

SACHS, I. Caminhos para o desenvolvimento sustentável. Rio de janeiro: Garamound, 2000.

SÁ-SILVA, J. R.; ALMEIDA, C. D.; GUINDANI, J. F. Pesquisa documental: pistas teóricas e metodológicas. Revista Brasileira de História e Ciências Sociais, v. 1, n. 1, p. 1-15, jul. 2009.

TRAJBER, R. Vida sustentável: ações individuais e coletivas. Espaços Educadores Sustentáveis, v. 21, n. 07, p. 22-29, jun. 2011. Disponível em: http://www.nuredam.com.br/files/documentos_ 
mec/194055espacoseducadoressustentaveis.pdf.

Acesso em: 18 jan. 2018. 